\title{
HOMBRE, SOCIEDAD Y DERECHO EN LA FILOSOFIA DE XAVIER ZUBIRI (*)
}

En los últimos años, la filosofía del derecho y de la sociedad en España ha sentido, en una de sus direcciones, el influjo de la lucidez metafísica de Xavier Zubiri. Esa dirección no significa, por lo demás, un intento de justificación de una realidad social y jurídica dada. La filosofía de Zubiri, como la de aquéllos teóricos de la sociedad, del derecho y del estado que de ella han partido, no debe apenas nada a las circunstancias. Estas suponen, quizá, ese sentirse "radicalmente solo", para "tener la capacidad de estar radicalmente acompañado", el ámbito donde ha podido realizarse, en España, la profundización evidente en estos temas fundamentales de la problemática humana.

El hecho de que Zubiri sea un discípulo de Ortega y Gasset, y de que se haya hecho de él un continuador de la línea de pensamiento de nuestro "filósofo castizo", ha podido llevar al convencimiento de una identidad de sentido en ambos filósofos. Su punto de partida es idéntico: la problemática "a la altura del tiempo" que Ortega había introducido en el pensamiento español del siglo xx. También observamos una similar forma y un diverso contenido: inteligencia sentiente (Zubiri) razón vital (Ortega). Las divergencias se manifiestan a diversos niveles.

Por una parte, en cuanto al método, Ortega mantiene frente a la inducción y a la deducción, el criterio hermenéutico de la razón histórica. La contextura de la realidad humana es historicidad. La aplicación del método histórico de la descripción como resultado. Por contraste, en Zubiri, que tampoco deduce, sino que describe, se parte de la realidad de las cosas, ante las que un realismo metódico, capaz de evitar todo conceptismo, deviene realismo metafísico. El punto de par-

(*) Ponencia presentada al XIII Congreso Internacional de Filosofía, México, 7-11 de septiembre de 1963. Cfr. lo indicado sobre el mismo tema por LeGaz, L.: Die Tendenzen der Rechtsphilosophie in Spanien in den letzten zehn Jahren, en "Archiv für Rechts-und Sozialphilosophie": XLV/3 y 4 (1959), 431-438. 
tida en Ortega es lo que las cosas van siendo; en Zubiri, lo que son las cosas que van siendo. Para Ortega, la filosofía "no es ingénita o connatural" al hombre, sino-aplicación del método histórico-ocupación a la que se vio forzado el hombre a partir del siglo Iv antes de Jesucristo. Zubiri, admitiendo como Ortega que la verdad supone un sistema de posibilidades con que la inteligencia afronta la realidad, sin embargo, no toma la filosofía como saber de esas posibilidades, sino de aquello que actualiza el afán del hombre de "acercarse a las cosas e interrogarlas"; la verdad. La filosofía es quehacer humano, despliegue de una inteligencia poseida por la verdad.

Además, en la metafísica orteguiana, al intentarse superar el realismo y el idealismo, ser significa vivir y vivir es estar "yo" y el "yo" de cada uno en la "circunstancia". El hombre no tiene naturaleza, sino historia, no tiene razón, sino que adquiere razón. En última instancia, el silencio envuelve la consideración última sobre que sea el mundo donde se articula el ser para de los otros. En Zubiri, por contraste-una "tercera metáfora" metafísica-, la existencia humana no es ni un trozo del universo (pensamiento griego), ni tampoco una envolvente virtual del universo (idealismo), sino que el hombre es la luz, a cuyo foco las cosas son: esa luz ilumina el ser de las cosas, no del "yo" haciéndolas trozos míos. Siempre dentro del tema del hombre, si su ser, para Ortega ha de consistir en su vida, que no es lo que tiene sino lo que es, para Zubiri en claroscuro, el hombre es una realidad "propia"-siempre se es el mismo-, más o menos apropiada por la persona: no siempre se es lo mismo.

Zubiri se pregunta, en última instancia, en qué consiste la razón de la existencia humana como luz de las cosas, que es lo que está más allá del ser. Pregunta que, consecuente con su metafísica, no se formula Ortega, para quien tal última instancia es un punto de vista de los hombres-ello son los órganos visuales, de la divinidad-sin consistencia metafísica alguna. La vida es decurso, sin origen ni fin. Para Zubiri, la nihilidad ontológica del hombre es radical: estamos obligados a existir porque, previamente, estamos religados a lo que nos hace existir. Esa religación es el fundamento de la existencia. Entendernos a nosotros mismos es no sólo entender lo que hay, sino, en última instancia, entender lo que hace que haya. Esa existencia religada es, en antítesis a Ortega, una "visión" de Dios en el mundo y del mundo en Dios.

En último lugar, refiriéndose al obrar del hombre en sociedad. Ortega mantiene que cada uno tiene que llegar a realizar la forma que le corresponde, su autenticidad: qué es lo mejor sólo podrá decirlo la 
razón histórica concreta de mi vida personłl. ¿Y el "otro"? Al "otro" lo abordo auténticamente como un "tú" y constituye precisamente, por contraste, mi autodescubrimiento. Pero esto no es lo social, sino lo irresponsable. Lo social queda relegado a lo humano inauténtico. El derecho y el estado son usos fuertes, usos que nos facilitan una serie de soluciones prefabricadas ante las situaciones vitales, pero que no tienen un fundamento metafísico en la persona. En este punto, el pensamiento de Zubiri cavila por otros derroteros: la historia es lo más opuesto al puro desarrollo. En la historia no sólo se producen actos, sino además, anteriormente, las propias posibilidades que condicionan su realización. El pasado se reduce, así, al conjunto de posibilidades del presente. Todo ello en virtud de que la razón del acontecer nos sumerge en el abismo ontológico de la realidad humana, fuente de sus actos y de sus posibilidades. Lo social- "hechos sociales"-, por ser una disposición de las potencias humanas, es objeto de manejo y organización. Lo histórico - "acontecimientos sociales"-es la actualización de las posibilidades de la convivencia humana: sólo hay historia cuando el hecho social es actualización de posibilidades y proyectos.

Desde una misma altura, pues, Ortega y Zubiri operan ante diversos horizontes. Podríamos decir que la filosofía de Ortega se inscribe en el círculo de las filosofías de la existencia, mientras que la de Zubiri, en el de las filosofías de la esencia.

\section{Filosofia segunda.}

El impacto de la filosofía zubiriana sobre el pensamiento español provocado a partir de la publicación en 1942, en el volumen "Naturaleza, Historia, Dios", de una serie de artículos, así como por los cursos privados iniciados en 1945 , ha dado en el blanco de la problemática en torno al hombre. Esa filosofía en torno al hombre y al espíritu como formas de realidad-filosofía segunda-llevaba implícito el bagaje de una filosofía de la esencia que sólo en diciembre de 1962, al publicarse, "Sobre la esencia", se ha explicitado. El camino anterior ya recorrido, va a ser el que ahora se describa. Lo "fundante y fontanal" de ese camino ha sido dado a conocer ahora de forma sistemática. De ambas etapas vamos a referimos, en torno al tema que nos ocupa.

Zubiri ha elaborado una auténtica antropología. La individualidăd es, para él, una conquista progresiva de la evolución del mundo físico. Esto, sin embargo, no significa que de la individuación de la materia 
- primer nivel o de los cuerpos físicos-se pase sin solución de continuidad al segundo nivel o de los cuerpos vivos; sustantivación de la materia. El cuerpo vivo se caracteriza por la sustantividad (unidad orgánica de estructuras y funciones) y la conducta o habitud, modo de respuesta vital al ambiente, modo de habérselas con las cosas. Ese modo se reduce, bien a nutrirse (vegetal), sentir (animal) o inteligir (hombre). Pero el animal no es prólogo del hombre. En el modo de habérselas con las cosas, el animal sólo tiene, por su función de formalización (independencia respecto al medio y centro específico sobre él), reacciones ante estímulos. En su tono vital, sin embargo, no hay exterioridad, porque, previamente, no hay interioridad. La línea de continuidad en lo físico entre el hombre y el animal, no corre paralela a un grado simplemente más elevado de formalización.

¿Cuál es la radical estructura sustancial-formalmente plural: tiene cuerpo y alma-que hace posible la sustantividad-formalmente una: es cuerpo y alma-humana? Por tratarse de un ser vivo, da una respuesta adecuada al medio, pero dentro de una hiperformalización: las cosas no sólo se le presentan como estímulos, sino como realidades. De ahí que la respuesta humana al medio haya de ser siempre problemática, ya que se hace cargo de él, como realidad, es decir, poniendo en juego su inteligencia sentiente. Tenemos que inteligir, pues, para asegurar nuestra sustantividad. En virtud de la inteligencia-modo radical y último de enfrentarse con las cosas-, el hombre es animal de realidades, consiste en sustantividad.

Ahondemos en el carácter formal de esa sustantividad. Ella significa que el hombre es una realidad personal. Personalidad no es riqueza mental, sino lo que se expresa con el personal "yo". "Yo" distinto, no sólo numéricamente de los otros "yos" personales, sino cualitativamente. Se trata de una distinción formalmente personal: "yo", "tú", "el" son intrínsecamente un "mí", "tf", "sf". Ese "mí" es una vivencia que envuelve un momento de mismidad, entendida no como identidad conmigo mismo, sino como intimidad: la estructura real, pre-vivencial de la realidad que soy; realidad que me es propia, realidad sustantiva en propiedad, que constituye la persona. Si esa realidad me es propia, no consiste meramente en propiedad, sino que consiste formalmente en ser propiedad en cuanto propiedad. Esto es lo radical: soy mío, porque soy mismo.

Si seguimos en nuestra meditación, habrá que dar razón de lo constitutivo de esa sustantividad personal. Su razón de ser reside en la inteligencia. Una realidad que tiene como propiedad la inteligencia, con- 
siste formalmente en ser "propiedad", en ser suya, sustantiva, por la inteligencia. La inteligencia sentiente que hace del hombre un animal de ralidades, hace de él, también, un animal personal.

Concepto de persona no puramente operativo (el sistema de acciones mediante el cual el hombre vaya adquiriendo su figura propia), sino constitutivo (carácter estructural de la realidad personal, gracias a la cual los actos pueden ser personales). A lo constitutivo, lo "propio", se denomina personeidad (siempre el mismo), y a lo op srativo, que supone previamente lo constitutivo, se le denomina personalidad (no siempre lo mismo). La personalidad tiene entidad porque la vida lo es de una realidad propia y puede ser más o menos apropiada por la persona.

Por último, completando sumariamente esta antropología zubiriana, el hombre se halla situado en pertenencia propia frente a toda realidad y control sobre ella. En esta dimensión es un absoluto. Pero por tratarse de una sustantividad constituida por sustancialidades, esa pertenencia es esencialmente relativa. El hombre, animal de realidades y de sustantividad personal, es un "relativo absoluto".

\section{Los actos del hombre.}

Cual sea la riqueza y la capacidad de despliegue de esa filosofía nos lo muestra la brecha fecunda de pensamiento que va abrir en la parcela intelectual española que restreamos: la sabiduría como ética.

La "Etica" (1958) de J. L. L. Aranguren se inserta a sí misma "en una tradición cuyos eslabones son Aristóteles, Santo Tomás y Zubiri". La inmoralidad-no así la inhonestidad-, aplicada al hombre, es un contrasentido, porque el hombre es constitutivamente una realidad moral. La realidad moral no es un "ideal", sino una necesidad, una forzosidad exigida por la propia naturaleza, por la propia estructura humana. El hombre tiene que ajustar el acto a la situación: sus actos deben ser coherentes con ella. De ahí que toda obligación moral, si de hecho viene impuesta por la sociedad, sin embargo, no puede traer su origen de la sociedad: ésta no podría imponer deberes si el hombre no fuera previamente una realidad "debitoria". El hombre está obligado al deber, porque está ligado a la felicidad. La "ligación" es natural: la "obligación" subsiguiente también: es imposible prescribir deberes a una mesa. En esto consistiría la moral como estructura.

Pero además de la moral como estructura (realidad primera), hay la moral como contenido (realidad segunda). Su felicidad constitutiva 
debe buscarla el hombre-inteligencia sentiente-concreta, históricamente: la moral de este hombre limitado que soy yo, es necesariamente "indeterminada". La moral como estructura reclama un contenido: la "idea del hombre" vigente en cada época. Idea que se nutre de elementos religiosos y de "inclinaciones" naturales (felicidad, ley moral natural), así como de otros condicionamientos situacionales e históricos. Esta "materia" moral dabe justificarse metafísicamente (como inscrita que está en la realidad) y exige esclarecer con precisión la necesaria abertura de la moral a la religión (dado que el hombre es una realidad moral y una realidad religada).

Esa doble dimensión de la moral hace que el hombre, sin salir del plano moral, proyecte históricamente diversas "ideas del hombre" y de su "perfección". En el hombre residen no sólo las potencias (estructura moral), sino también las posibilidades de la actualización histórica de esas potencias, según diversas líneas de desarrollo. Unas veces se trata de mera explicitación de posibilidades comprendidas dentro de una idea de hombre. Otras, cuando la moral se deforma, no cabe más salida que un cambio radical de la sociedad, implicado por un cambio radical de la idea de hombre. $\mathrm{Y}$ también, manteniéndose incólume la exigencia de perfección, pueden variar las "ideas de feliciđad", o los desarrollos de una de esas ideas, vigentes en un momento del decurso histórico. Por eso, aun sin salir del plano moral, el hombre necesita de la Revelación y de su histórica explicitación, que va patentizando más y más el contenido de la moral.

Un filósofo de la historia, J. A. Maravall (Teoría del saber histórico, 1958), emergiendo del pensamiento de Zubiri, ha abundado en esa problemática histórica del hombre, que le amenaza como un determinismo o le tienta a huir hacia una quietud mostrenca, de espaldas al acontecer dinámico. La histórica es, así, un intento de interpretación de los hechos. Desde las posibilidades inherentes a su situación, y partiendo de los que es radicalmente, el hombre proyecta sobre la realidad exterior, actualiza sus posibilidades. El pasado se desrealiza y queda como posibilidad del presente. Mientras acontece, el hombre es lo que le queda de suyo, después que le ha pasado todo lo que le tiene que pasar. Aquí Maravall, aunque no admite una indeterminación física plena es partidario de la causalidad histórica, más cara a Ortega, frente a ese "lo que le tiene que pasar" de Zuburi. En todo caso, es esa visión del hombre, aprehendida en Zubiri, como transcendencia de su ser respecto de su propia vida, la que le hace concebir la histórica como liberación. 
Pero volvamos a la "realidad moral" que el hombre es. Sus fibras más íntimas han sido miradas, en actitud envolvente, por P. LAIN ENTRALGo (La espera y la esperanza, 1953; Teoría y realidad del otro, 1961). El hombre no es cuerpo y alma, sino cuerpo y alma. La unión cuerpo y alma es unidad primaria: para que el hombre, en cuanto individuo sicosomático, no se pierda entre las innumerables posibilidades biológicas que le ofrece y le impone su alta capacidad de formalización, es necesario que su existencia sea un "hacerse cargo" de la situacion y, por tanto, que opere en ella una genuina inteligencia. Esa unidad primaria es la estructura fundamental del hombre.: la regulación de la estabilidad de su tono vital. El hombre es autor, actor y agente de su vida. Como fundante de "lo que hay", hay "lo que es" y "lo que hace que haya". La existencia es, así, no impuesta, sino propuesta: el hombre es capaz de revelarse contra sí mismo, contra su ser, en la medida en que ya existe. Ese revelarse, esa desconfianza de sí mismo, viene entendida dentro de esa estructura del hombre que implica lo síquico y lo somático. Un hombre será habitual y expresamente esperanzado cuando sepa descender a través de su vida (lo sicosomático condiciona, no obstante, este descenso) hasta la radical simplicidad, fontanal y religante, del ser personal, y acierte a descubrir allí que su espera (hábito de primera naturaleza) es constitutivamente "fianza", y aceptando ese descubrimiento, quiera elevar la "fianza" a "confianza" (su inteligencia coligente conduce a la esperanza a reposar en "algo" referido a "todo" a que ese algo pertenece). La desconfianza, el drama humano, es discrepancia entre "vida" y "ser". La "espera" es la "fianza" en el "ser"; la "esperanza" es confianza en "seguir siendo".

¿Se ha de esperar en el "otro"? Depende de cómo se le aborde. Si el otro es tomado como objeto-simple "él"-, lo naturalizo: coexistir con él es desarraigar de él sus posibilidades y apropiárselas: el "otro" es instrumento y espectáculo. Si lo abordo como persona, mi relación es de coejecución, conocimiento. Pero "persona" es simple máscara; la vida personal del "otro" se me escapa, y mi vida personal escapa al "otro". Pero si lo abordo como próiimo, entonces mi relación se establece no con tal hombre determinado, sino con cualquier hombre. En esa relación de projimidad, en el orden antropológico y moral, la creencia-el acto personal por el cual atribuimos existencia a lo no patentees el supuesto: creo a un hombre por el hecho de serlo. Estamos en los umbrales de la relación social auténtica. 


\section{Hombre en sociedad.}

La sociedad, el estado, el derecho son dimensiones, en expansión, del hombre. Las ideas de Zubiri han removido el pensamiento español contemporáneo en torno a estos temas, que una filosofía horizontal pretende relegar a la inautenticidad. Cuando la conversación sobre la res publica no se apoya en el qué de las cosas, sino en como aparecen ante los hombres, en la opinión, entonces no hay diálogo sino disputa, no hay política sino retórica.

J. CONDE (El hombre animal político, 1957) caracteriza la coexistencia como dimensión formal originaria del ser del hombre. Este se encuentra "abierto" a las cosas (lo que circunscribe sus posibilidades) y a los "demás" hombres (como consecuencia de sụ "nihilidad" ontológica); la coexistencia no es una necesidad de mi razón, sino una dimensión formal del ser humano). El hombre "proyecta" en común, y realiza actos "comunes" con los demás hombres. Ese hacer en común presenta una doble vertiente: a) ejercicio de la potencia correspondiente (resultado: hecho social), b) hacer libre dentro de ciertas posibilidades (acontecimiento social, hechos históricos). La realidad social es así, la actualización de la potencia que el hombre tiene de convivir con los demás en lo que esa actualización tiene de puro ejercicio, de habitud, de respectus para con los demás, En un estrato superior están los actos comunes "históricos", que no son actualización de potencias, sino ejercicio de posibilidades. Aś, los modos posibles de coexistencia-proyectos-descansan en la misma estructura del hombre, en ese su ser "por" y "para" los demás. En todo caso, sin embargo, la coexistencia no agota el ser del hombre: es sólo una de sus dimensiones formales.

La realidad social no es, pues, extraña al hombre, sino la resultante de actos "sociales" de la persona humana. Acto social no precisamente reactivo, sino proyectivo. La realidad social, por ser humana, se plasma en un histórico proyectar en común, que cuaja en unidad de acción y de decisión.

En esta misma línea zubiriana, E. Gómez ARboleya (Estudios de teoría de la sociedad y del estado, 1962), ha formulado una teoría del grupo social, situada en el centro de su sociología. Partiendo de la unidad no meramente natural, sino personal, del hombre, éste se halla referido a otras personas: es una intimidad abierta. Este es el fundamnto ontológico de la realidad social, aquello que nos permite acercarnos precientíficamente a la experiencia científica: no se trata de ver el color, sino 
lo coloreado. No observamos propiedades, sino cosas. O, más bien, las cosas se constituyen en objeto de experiencia cuando el hombre, presupuesto el carácter sintáctico de la realidad, investiga lo propio de cada cosa, su sustantividad 'y sistema. La sociología debe tener en cuenta que el hombre está abierto a una realidad propuesta, por lo que se hace factible la constitución de la cultura. La sociología no es sólo ciencia formal, sino lógica del conjunto constituido por la realidad social, que se presenta realizada históricamente y en grupo (la forma -individuo-no puede separarse del contenido: grupo). El objeto de la sociología son, en conclusión, los grupos humanos como realidades efectivas y concretas, es decir, configurados en cierta manera (posibilidades) por la obra del hombre (potencias actualizadas). El hecho social, en todo caso, es puesto por el hombre, conectado con todos los factores como totalidad (el fenómeno social es vida humana), y elemento en un proceso continuo e irrepetible (la libertad es exigida, sin que ni el hecho de no poder forzar la realidad social ni su estructura contra sí misma, ni el hecho de contar con un conjunto restringido de posibilidades reales, la menoscaben: la realidad social postula una causalidad exigitiva).

Pero con todo ello no hemos hecho sino poner las bases de la realidad política. Conde se pregunta por la naturaleza de la misma. Debe encontrarse un criterio objetivo de configuración. Pues bien, cuando arrojo sobre la realidad social el proyecto que entraña un acto político, ese proyecto se convierte en motor de otras voluntades. Lo político, evidente en esos efectos objetivos producidos, consistiría en "la organización autónoma del obrar común de los hombres partiendo de una idea determinada del derecho, conforme a un plan y dentro de un espacio concreto". A este resultado se llega después de admitir que los actos sociales, por partir de una habitud, se decantan y devienen modos de conducta en común relativamente consistentes, regulados, ordenados (de acuerdo con el carácter sintáctico de la realidad). Esa regularidad no sólo es efectiva, sino legítima: está determinada por la idea de que en sí misma es legítima y debe seguirse. Regularidad u ordenación que, dados un plan y un espacio enlazados en la idea del derecho, operaría el tránsito a la verdadera unidad del obrar social colectivo: organización. Esta no es pura forma: la realidad política sólo es positivamente valiosa cuando esa unidad de organización reposa en una voluntad cargada de eticidad. Capaz, por lo demás, de conferir a la idea absoluta de la justicia, en que el derecho consiste, la precisión que convierte la validez en vigencia, dentro de una situación histórica concreta. El 
valor de lo político no consiste sino en decidir en cada caso (problema de las formas históricas de organización política), con proyectos de coexistencia, qué sea derecho en razón del tiempo, del lugar, de las personas.

\section{El derecho del hombre.}

Si el derecho queda como horizonte de la dimensión social del hombre, es porque ontológicamente está enraizado en el hombre. Esa metafísica del derecho, impostada en Zubiri, ha sido llevada a cabo por L. Legaz Lacambra (Filosofía del derecho, 2. ${ }^{a}$ ed. 1961). El hombre, ya sabemos, entre la naturaleza y la existencia personal (a la que está ligado, y por la que está fundamentado), traza la trayectoria de su vida y de su historia. Por otro lado, lo social, el "con", es una de las características ontológicas formales de la persona humana. Pero si lo social presupone esa dimensión de coexistencia, no consiste en coexistencia. La vida humana transcurre en los planos ontológicos de vida personal y vida social, que se diferencian entre sí en el modo de relación con los demás. En la vida personal, el hombre vive el hecho radical de la coexistencia desde su propio centro de intimidad personal, del cual emana la norma y la forma de su comportamiento ante y entre los otros. La vida social-que si no es vida auténtica, es auténtica vida-consiste en el conjunto de soluciones que han dado a los distintos problemas sociales "todos los demás" y que, por lo tanto, se encuentran ya resueltos: consiste en mandatos, preceptos y usos impersonales.

Tanto la vida personal como la vida social vienen sometidos a normas, pero de distinta forma. En la vida personal, el sujeto está ante las normas como ser libre. En cambio, en la vida social, no es la libertad, sino la norma lo que la caracteriza esencialmente, estando justificada esa norma por constituir una necesaria dimensión del existir. De donde el derecho se configurará como forma necesaria del vivir social (ubi homo, ibi ius). El quehacer humano se desenvuelve en la vida de relación necesariamente en forma jurídica. $Y$ esto en un doble sentido: como vida en forma y como vida formadora, como estructura y como actividad.

Dada la estructura moral, de la persona, las normas jurídicas de convivencia deben justificarse a sí mismas. Entre los valores éticos y la persona debe integrarse el modo social de la vida del hombre. Pero la justicia, el no poder realizarse como tal en la vida personal, requiere el modo de ser del derecho como forma social de existencia. Entonces, 
el derecho es punto de vista sobre la justicia, justicia vista en cierta perspectiva.

Llegados a este nivel, siguiendo el pensamiento zubiriano, Legaz conecta la realidad social, la realidad política y la realidad moral que el hombre es. A partir de la metafísica de la posibilidad, se llega a la conclusión de que existen para el hombre una serie de pos sbilidades que son obligatorias en razón de aquello que religa la existencia humana a lo que la hace existir y a lo que determina su modo de existir. Pues bien, mientras la obligación juridica es una posibilidad con opción (porque el uso de la posibilidad contraria no destruye la condición de sujeto de derecho conceptualizada por la norma jurídica), y la obligación moral es posibilidad con relativa opción (todo desorden moral se produce dentro de una situación que sigue siendo moral), la obligación política, determinada por la integración existencial en un complejo de poder, es una posibilidad sin opción: tanto si no se acata el orden instituido, como si se claudica ante el poder que ha perdido la justificación de su existencia (conexión del poder, con la justicia y con el bien). En este punto, siguiendo a Zubiri, es lúcido el análisis de J. FuEYo (Orden político y norma constitucional, 1960), para quien la impresión de realidad en que el hombre se hace cargo de lo político descubre la conexión entre el hecho político y una totalidad orgánica. Totalidad remitida a otra estructura total: el mundo.

\section{Filosofía primera.}

La filosofía de Zubiri, que ha hecho posible este despliegue, era sólo filosofía segunda, que llevaba implícita una filosofía primera, o de la realidad a secas, explicitada ahora en "sobre la esencia". Para Zubiri, lo primario no es la sustancia, sino, como ya sabíamos, la sustantividad: sistema de notas-propiedades, partes y momentos-de la cosa. En este sistema no se incluyen las notas adventicias. De entre las constitutivas, que son todas "notas de", unas son infundadas y reposan sobre sí mismas, otras se apoyan sobre éstas. Al subsistema que las primeras forman, dentro del sistema, llamamos esencia, lo propio de cada cosa. Pero sobre esa realidad se piensa: problemática de la especie. La especie metafísica, a la manera biológica, está constituida por las notas transmisibles a otras sustantividades: las esencias individuales derivan de otras individuales y tienen algo en común. El conocimiento será, por tanto, de las notas constitutivas, será una descripción de la realidad formulada en proposiciones esenciales. De ahí su limitación, ya que pocas 
veces sabremos si hemos descubierto verdaderamente una nota constitutiva y nunca podemos estar seguros de haber dado con todas.

La realidad viene considerada hasta ahora como mera estructura transcendental: es "de suyo". Pero además la realidad tiene un segundo momento transcendental: la respectividad o mundo: la actualidad de lo ya real en sí mismo, como momento del mundo, es el ser. Antes del ser está, pues, esa estructura transcendental de la esencia: la esencia es "de suyo" suya a su propio modo; es además "de suyo" una interioridad en exterioridad; es a su vez cerrada y abierta a su carácter mismo de realidad.

Esa estructura es no sólo de las notas constitutivas de la realidad, sino de las adventicias, que consisten en actualización, en posibilidades: el hecho es la actualidad de una potencia. La esencia humana abierta es principio "de donde" algo es suceso. Sin esa estructura positiva de la realidad humana "de suyo" no habría ni sucesos biográficos, ni historia: la historia no sería formalmente humana.

¿Qué queda en esa esencia abierta, que es el hombre, de la nihilidad ontológica que hacía referencia a su implantación radical en el ser, al esse? Aquí, la fundamentación ontológica de todo valor, y subsiguientemente de la dimensión social del hombre, tiene comprometida su alcance. En la dirección de la realidad, Zubiri asume el punto de vista de su unidad, y al considerar a Dios como el supra-ser, parece mantener el extrinsecismo de ese supra-ser respecto a la realidad. De ahí que no distinga, sino racionalmente, entre lo meramente rato (esencia en abstracto) y lo meramente existente (esencia concreta realizada). Estando situado Zubiri ante un horizonte realista, tal extrinsecismo le llevaría quizá, paradójicamente, a una dirección platónica. A lo sumo, dentro de esa distinción conceptual, el trasfondo pudiera ser una mera dependencia causal de religación respecto al supra-ser, siempre en la línea del extrinsecismo. Cuestión en la que está en juego la problemática primigenia de la filosofía, el esfuerzo de Parménides: el esse. En todo ente causado subsistente ("de suyo"), esse difiere realmente de esencia, porque la realidad participante difiere de aquello de lo que participa (intrínsecamente fundante $\mathrm{y}$ fontanal).

La meditación zubiriana nos ha llevado muy lejos, a través del tema del hombre. La meditación zubiriana, lúcida y concreta, nos ha convencido una vez más de esa actitud del saber filosófico, según él, anhelante, siempre "constitutivamente inmaturo".

Juan José Gil Cremades 